\title{
Democracy Discourses through the Internet Communication: Understanding the Hacktivism for the Global Changing
}

\author{
Nofia Fitri* \\ Department of Political Science, National University, Indonesia
}

\begin{abstract}
The global communication via internet has been fostering the political participation of the public civil into the world orders through several different ways; include the participation of computer virtuosos, called hackers, who have been sponsored the emergent of a new social movement 'hacktivism' as a new interest phenomena for the media communication and technology field. This article aims to describe the hacktivism movement as one of the ways of civil people to participate into the global politics through the public sphere, communicate their ideas and promote the principles of democracy using the technology of hacking computer. Within this article I focus on several hacktivism activities emergent since 1990s. My findings have revealed that the hacking politics actions and the social-humanity messages were conveyed by the hactivists encouraged the global circumstances for being more aware and concern on the democracy discourses. Hence I shall conclude that in the modern era of communication and technology the hacktivism has been emerging to promote the freedom of people through the internet and distributes the democracy principles into the global world for the global changing.
\end{abstract}

Keywords: Democracy, Internet Communication, Political Communication, Hacktivism, Public Sphere and Global Changing.

\footnotetext{
"Imagine if computer hackers, the daredevils of the networked world, suddenly became principled political activists; if they had a mission besides breaking and entering; if they had more to prove than that they are smarter than whoever designed your computer system, if their targets were selected as part of well organized, thoroughly researched, international human rights campaigns.” (Naomi Klein)
}

Long after Naomi Klein (1998) noted the computer hacking as a new tool of political activism, Robin Mansell trough his research "Communication and Technologies, What is New?" highlighted the current issue within the communication and technology field. One of 
them as he cited is the relation between communication, technology and governance. He stated "the governance of online media influences how new technologies become embedded in society" (Mansell, 2007:8). Followed the statement, he mentioned that hacktivism and cyberterorism were two of the most visible debates appearing in the media as the implication of the technological innovation in the recent days.

For his purposes, Mansell used the definition from Taylor and Jordan (1999) which hacktivism defined as "the conjuction of hacking techniques with the values communicative strategies of political activism in line with the agendas of new globalized social movement." Doroty E. Danning (2001) who concern on the issue of the hacktivism, activis, and cyberterrorism and their relation with the global changing by focused on the foreign policy analysis stated that:

"In the area of hacktivism, which involves the use of hacking tools and techniques of a disruptive nature, the internet will serve mainly to draw attention to a cause, as such incident are regularly reported by news media. Whether that attention has the desired effect of changing policy decisions related to the issue at hand is much less certain."

According to some scholars, hacktivism would be a single politically motivated virtual action of non-state actors in order to gather public attention for a political topic and to express disapproval. For example, as Taylor stated (2005: 4) "it engages with this metasystem directly and, with its close ties to the politics of globalization, marks the beginning of a significant new chapter in radical technological politics." Use an explanation of Taylor, furthermore because of the radicalism claim, for the global society the hacktivism is not that quietly accepted, while some scholars even marked this new social movement as a part of criminal actions.

Therefore the hacktivism have been attracted more repulsion than acceptance whereas the motivations behind are not to sabotage, destroy or permanently cripple government operations as what several media ever been published, but more to bring attention to freedom, violations of human rights and to protect the responsible flow of information on the internet. Thus the hacktivism movements stick together with the issue of democracy in the modern era. 
This article traces the emergent of hacktivism as a new phenomenon on the study of communication, media and technology in the modern era. As I interest on the distribution process of democratic values through the media of internet, I then attempt to examine my findings on the hacktivism activities, for their roles in conveying several political messages to the global world about their understanding on democracy.

I firstly describing the democracy discourses through the cyberspace, which internet is an effective media for the global communication. I then describe a very brief history about the emergent of hacktivism movements and their ideologies before accommodate those actions with the conception of electronic democracy, democracy deliberation and the role of public sphere. I may focus on the Habermas' theory about the public sphere and democracy deliberation then use a theory of political communication to bring this issue into the main purpose of this article that is describing the hacktivism as one of the important tools to promote the democracy values through the internet.

\section{Democracy Discourses through Global Communication}

Today we are living in the modern era wherein democracy becomes a controversial public debates, especially regarding on the relation between citizens and government. Could citizens control the government as what the democracy ideal is? Or on the contrary the government serves the citizens by several policies and regulations which control the freedom of citizens. Democracy discourses would never stop to debating the relation between government and citizens since among them emerging the conception of the participation of social order. For this purposes, people would never fed up to communicate each others, talk about democracy and attract many people to participate into this debate.

The global communication has been quietly useful for the debate on democracy discourse, especially to highlight the implementation of democracy while the democracy itself still in the controversial debate circumstances. For taking over this controversial, there is a popular quotation can reflects the meaning of democracy as many scholars often cited, from John Dewey (1999) "democracy is not an end in itself, but a means by which people discover and extend and manifest their fundamental human nature and human rights. Democracy is rooted in freedom, solidarity, a choice of work and the ability to participate in the social order." 
Shall we then conclude that the concept of democracy has been doing an expansion from the traditional old Greek into the modern world? Democracy today does not only seem as what Plato ever described, about the majority and minority. Democracy is the process which all people can participate; include for control the government itself. Thus the public sphere is important for the future of democracy discourses.

A study on the democracy and public sphere has been done by many different scholars with different backgrounds. But the most popular one may a quotation by Habermas. "The age of the public sphere as face-to-face talk is clearly over: the question of democracy must henceforth take into account new forms of electronically mediated discourse. Poster (Poster, 1995) based on the Habermas' theory put a question "what are the conditions of democratic speech in the mode of information? What kind of "subject" speaks or writes or communicates in these conditions?" While Cohen (1998) pointed out that freedom of speech is even more crucial to deliberative democracy. He summarizes the arguments that have been made for the importance of freedom of political expression in a democracy:

1. Democracy is based on the principle of popular sovereignty, which demands "free and open discussion among citizens";

2. Restricting speech creates political inequality between those whose speech is allowed, and those whose speech is restricted;

3. Restricting speech impedes the free flow of information, "perhaps reducing the quality of democratic discussion and decision", and

4. Restricting speech limits the range of ideas or opinions in a political discussion. (Cohen 1998)

\section{Political Communication, Public Sphere and Internet's Roles}

Monroe Price, a professor and director of the Centre for Global Communication Studies University of Pennsylvania within his interview was asked about the political communication challenges in the $21^{\text {st }}$ century. He stated "we will have new models of politics, new concepts of involvement, new technologies that create these changes, and we may have huge tension in our societies" (Price, 2010: 2).

To describe how the political communication's works use the internet media as a public sphere let me first put a clear conception about political communication itself. As defined by 
Graber (2002: 479) political communication is "encompasses the construction, sending, receiving, and processing of messages that potentially have a significant direct or indirect impact on politics." He then explained that "the key element is that the message has a significant political effect on the thinking, beliefs, and behaviors of individuals, group, institutions, and whole societies and the environments in which they exist." The question now "how does the internet as an important public sphere work for the political communication?"

According to Brunstibg (2002: 550) the internet is a great tool for generating popular support for activist causes in a non-violent way, as he stated "the internet changes the nature of collective action, but contrary to popular belief, the internet would appear to be especially suited of collective action rather than confrontational action." Therefore the internet permits an unprecedented empowerment of the individual. Thus through the internet, a political communication which involved public participations and the useful of technology could be describe in several ways, for instance blogger, individual websites, the community joint, responding the online newspaper up to the technical way, hacking computer and many others.

As Danning stated "the internet is clearly changing the landscape of political discourse and advocacy. It offers new and inexpensive methods for collecting and publishing information, for communicating and coordinating action on a global scale, and for reaching out to policy makers, supports both open and private communication (Danning, 1999: 26). Hence the Internet is not only a welcoming of global communication forum for the free exchange of views, but it has its own class of warriors dedicated to protecting free speech online.

In the case of Vegh's dissertation, the focus on media coverage of hacktivism is consistent with a theoretical agenda: to demonstrate the internet's challenge to elite control of mass communications. As a communications scholar, Vegh argues that "control of the media is crucial to the hegemony of political and economic elites: media control allows elites to repress alternative narratives of resistance or protest. The agenda of elite control leads mass media to skew their presentation of "counterhegemonic" online activities "toward a perspective that is favorable to the ruling powers, no matter how democratic or socially empowering these activities potentially are" (Vegh 2003).

Therefore the internet as an effective public sphere has provided either activist or common users new opportunities to build networks and to exchange alternative information or 
distribute counter hegemonic discourses in a more efficient way. And it also provided activists and civil society organizations more control over the content of their message and the tools to independently inform citizens and sympathizers world-wide. They might involve themselves into the political communication process in advance use the internet media for express the consciousness of politics of civil people.

\section{From Hacker to Hacktivists and Ideology}

"It is never the technical stuff that gets you in trouble. It is the personalities and the politics." (Rick Cook, Wizardry Compiled)

Considering the media's publications of the hacker's conceptions, firstly I do need to quote a short clear statement "a hack is a net programming trick and a hacker is a computer virtuoso, and it was a hacker that created the technology and computer programs that make up the internet we all take for granted today." (Paul Miller, 2001:4). We might have been found how did the media defined a hacker with a wrong perception, while there are many articles still ongoing published to make a clarification for it. For instance, some scholars even indentified hacker as a semi-criminal individual while on the contrary there was no computer innovations either internet revolution without the roles of hacker.

Hacker defines as "someone who enjoys tinkering with computers to find concrete solutions to technical problems" (Taylor, 1999). Hackers believe that they should promote the free flow of information, and causing anything to disrupt, prevent, or retard that flow is improper. Steven Levy (1984) through his famous book "Hackers: Heroes of the Computer Revolution" articulated the hacker tenets:

1. Access to computers should be unlimited and total.

2. All information should be free.

3. Mistrust authority - promote decentralization.

4. Hackers should be judged by their hacking not bogus criteria such as degrees, age, race, or position.

5. You create art and beauty on a computer.

6. Computers can change your life for the better 
Alexandra Samuel (2004) quoted a definition of hactivism from Graham Meikle (2000) as "the marriage of political activist and computer hacking" then described the hactivism as detail:

"An engaged politics which seeks solutions in software in the search for a specific technological fix to a social problem. So it refers to any use of computer technology for political ends, including diverse on-line practices: cross-border: information sharing, action planning and coordination via personal emails: chat rooms and electronic distribution list."

The way of hacktivism expansion from just a hacking politics into the new social movement in the modern era may reflected from the statement of analyst Ted Julian from Yankee Group which he said "when we look back years from now we'll see this as a tipping point in 'hactivism' going from largely a theoretical threat to something that's more a day-to-day issue." (Guardian, 2010).

Meanwhile Conway (2007) argued "hacktivists, although they use the Internet as a site for political action, are not cyberterrorists either. They view themselves as heirs to those who employ the tactics of trespass and blockade in the realm of real-world protest. They are, for the most part, engaged in disruption not destruction." Thus the things that hacktivist have been doing are to promote the freedom of information through the internet, to transform the message of hackers' beliefs about the future of world. Hence they are struggling for the global justice, human rights, and freedom.

The most familiar and prior hacktivism group may the Cult of the Dead Cow (CDC) who has sought to combine a humorous with a hardened attitude to corporate power on the Net. This group created "Goolag" a vulnerability software. They announced the release of Goolag Scanner, a webauditing tool which enables everyone to audit his or her own website via Google. The scanner technology is based on "Google hacking," a form of vulnerability research developed by Johnny I Hack Stuff (Metac0m, 2003). The method in which "Goolag" was released achieved four things; "1) an increased awareness of Website vulnerabilities, 2) an increased awareness of Google's compliance with censorship practices in China, 3) refreshed the public of the presence of the $\mathrm{cDc}$, and 4) promoted a tool that can be used for more constructive purposes." (Ranario, 2008). 
Another well-known hacktivism group is a Net based affinity group called the Electronic Disturbance Theater' (EDT). This group of hacktivist pushed and agitated for new experimentation with electronic civil disobedience actions aimed mostly at the Mexican government. They coordinated a series of Web sit-ins in support of the Mexican antigovernment group, the Zapatistas. EDT created the Flood Net software which internet users once downloaded on to an individual's computer automatically connects the surfer to a preselected Web site, and every seven seconds the selected site's reload button is automatically activated by the software. It worked by thousands of people use Flood Net on the same day, the combined effect of such a large number of activists will disrupt the operations of a particular site.

Those two hacktivism groups mentioned above are the most well-know since the hacktivism movement emergent. Following it, in the spring of 1998, a young British hacker known as "JF" accessed about 300 web sites and placed antinuclear text and imagery while Milw0rm broke into computer systems at India's Bhabha Atomic Research Centre, Bombay (BARC) in a protest against nuclear weapons tests. Kaotik Team defaced 45 Indonesian Websites to include messages calling for full autonomy for East Timor. In 1999, The ElectroHippies a group of hacktivist in Britain organised a cyber protest whereby anybody who wanted to could join together to repeatedly 'ping' the WTO website. They used the tehcnique of Distributed Denial of Service (DDoS) attack during the Seattle World Trade Organisation (WTO) protest.

The latest issue on hacktivism may the wikileaks phenomenon at the end of 2010. This whistleblower controversial was not only bring more attention on government and citizens relation about secrecy and leak but also the internet freedom, press freedom, democracy, and hacker culture. The hacktivism action as a response to the global constellation emergent through the Operation Payback to support the wikileaks. It appeared by the hacking action of the Anonymous-Anonops. This unorganized group of hackers attacked the VİSA, Mastercard and Paypal with denial of service attack technique (DDoS). In their efforts they organized the payback action through social Networks such Twitter and Facebook, and chating server IRC. In an online letter, Anonymous said its activists were neither vigilantes nor terrorists. It 
added: "The goal is simple: Win the right to keep the Internet free of any control from any entity, corporation, or government." (Reuter, 2010).

To understand the hacktivism as deeply we need to see the way of hacktivism itself put an attention into the hacking-computer and idealism on politics. These excerpts below are reflecting the main ideology of the hacktivism movements:

- The Cult of the Dead Cow, "The Hacktivismo Declaration"

"We recognize the right of governments to forbid the publication of properly categorized state secrets, child pornography, and matters related to personal privacy and privilege, among other accepted restrictions. But we oppose the use of state power to control access to the works of critics, intellectuals, artists, or religious figures...we will study ways and means of circumventing state sponsored censorship of the Internet and will implement technologies to challenge information rights violations." (Ruffin, 2001)

- The Electrohippies, "Client-side Distributed Denial-of-Service"

The structure of the client-side distributed actions developed by the electrohippies means that there must be widespread support across a country, or continent in order to make the system work. Our method has built within it the guarantee of democratic accountability. If people don't vote with their modems, the collective action would be an abject failure. Fundamentally, it's the mode of the protest on the Internet that is important when evaluating the legitimacy of the action. (DJNZ, 2001)

- The Electronic Disturbance Theater, "On Electronic Civil Disobedience"

As hackers become politicized and as activists become computerized, we are going to see an increase in the number of cyber-activists who engage in what will become more widely known as Electronic Civil Disobedience. The same principals of traditional civil disobedience, like trespass and blockage, will still be applied, but more and more these acts will take place in electronic or digital form. (Wray, 1998)

- The Anonymous-Anonops 
"We're against corporations and government interfering on the internet. We believe it should be open and free for everyone. Governments shouldn't try to censor because they don't agree with it. Anonymous is supporting WikiLeaks not because we agree or disagree with the data that is being sent out, but we disagree with any from of censorship on the internet. If we let WikiLeaks fall without a fight then governments will think they can just take down any sites they wish or disagree with. (Guardian, 2010)

\section{Electronic Civil Disobedience, Hacking Techniques and Political Messages}

"[We need], a future communications guerilla warfare - a manifestation complementary to the manifestations of Technological Communication, the constant correction of perspectives, the checking of codes, the ever renewed interpretations of mass messages. The universe of Technological Communication would then be patrolled by groups of communications guerillas, who would restore a critical dimension to passive reception. The threat that the 'the medium is the message' could then become, for both medium and message, the return to individual responsibility. To the anonymous divinity of Technological Communication our answer could be: 'Not Thy, but our will be done."'(Eco, 1967: 144)

The Electronic Civil Disobedience (ECD) represented the hacktivism as the way of civil people express their political consciousness. The phrase EDT was coined by a group of artists and theorists called the Critical Art Ensemble which in 1994 they published their first book that dealt with this subject, "The Electronic Disturbance." (Taylor, Ibid). EDC is a legitimate form of non-violent, direct action utilized in order to bring pressure on institutions engaged in unethical or criminal actions. Within the electronic environment, ECD aims to disrupt the operation of information and capital flows of carefully selected target sites without causing serious damage. 


\section{Table 1}

\section{Hacktivism Hacking Techniques}

\begin{tabular}{|l|l|}
\hline \multicolumn{1}{|c|}{ Civil disobedience: } & \multicolumn{1}{c|}{ Hacktivism: } \\
\hline Sit-ins & Web site defacements \\
Barricades & Web site redirects \\
Political graffiti & Denial-of-service attacks \\
Wildcat strikes & Information theft \\
Underground presses & Site parodies \\
Political theater & Virtual sit-ins \\
Sabotage & Virtual sabotage \\
& Software development \\
\hline
\end{tabular}

Several different techniques on hacktivism (Samuel, Ibid: 8-14)

Site defacements consist of hacking into a web server and replacing a web page with a new page bearing some sort of message.

Site redirects involve hacking into a web server and changing its addressing so that would-be visitors to the site are instead redirected to an alternative site, usually one that is critical of the hacked site.

Denial of service $(\mathrm{DoS})$ attacks are a common and powerful way to wreak online havoc, but have been only rarely used by hacktivists. A DoS attack is an attack on a computer system or network that causes a loss of service to users, typically the loss of network connectivity and services.

Information theft consists of hacking into a private network and stealing information.

Virtual sit-ins get hundreds, thousands, or even hundreds of thousands of protesters to rapidly reload web pages on targeted servers, overloading them with traffic until they slow down or crash. 
Site parodies spoof a target organization, often by imitating the appearance of its web site, and by locating the spoof at a URL (web address) that is likely to be confused with the address of the original (spoofed) site.

Software development can constitute hacktivism if the software tools serve specific political purposes. These tools are usually created and distributed as open source software, which means that they are free, and that anyone can modify the code allowing for collaboration and continuous improvement.

The point here is not merely the actions of the hacktivists have been taken, therefore we often consider with the dilemma among legal or illegal of hacking activities, but this article tries to emphasizing the messages they have been threw out to the global world. Their political consciousness appeared from the messages displayed through the victim websites. Yet website defacement is one of the main techniques hacktivist often to use for their purposes. Through this way, the group of hacktivist whether being organized as a settle of hacktivist group or independently established at the level of grassroot conveyed their political messages that fully contented of the human rights and anti-war, the democracy values.

The team sp10it hacked the government web and displayed a message "tell your governments to stop the war"; the Anti-Nuclear Hackers made a worm viruses againts the nuclear program and displayed a message "you talk oftimes of peace for all and then prepare for war." (Wired, 1998). The Milworm who attacked the Bhaba Atomic Research Centre displayed "a nuclear war does start, you will be the first to scream; the Asthray Lumberjacks hacked the British Internet Service with the message "use your power and keep the world in a state of peace and put a stop to this nuclear bullshit." (Ibid). The Wannabe Hacker Team, one of the Indonesian young hacker groups defaced more than 300 websites and displayed a message "Boykot Israel, Solidarity for Palestine." (eZINE, 2011). One group of hacktivists stated "we do not believe that only nation-states have the legitimate authority to engage in war and aggression. And we see cyberspace as a means for non-state political actors to enter present and future arenas of conflict, and to do so across international borders." (the Hacktivist, 1999).

In 1996 an anonymous hacker defaced the DoJ site to protest the Communications Decency Act (CDA) base on the CDA attraction to the ire of the Internet community with its 
provisions for screening offensive material online. The DoJ defacement protested the CDA with a range of images and invective, such as:

"Free speech in the land of the free? Arms in the home of the brave? Privacy in a state of wiretaps and government intrusion? Unreasonable searches? We are a little behind our 1984 deadline, but working slowly one amendment at a time. It is hard to trick hundreds of millions of people out of their freedoms, but we should be complete within a decade.("Site defacement, US Dept. of Justice" 1996).

Regarding on the political message conveyed by the hacktivists, they argued "I think hacktivism should be about delivering a message, just like good old grass roots activism. It shouldn't be about doing damage to someone else network, or taking away their right to express their views. We just want to make a fuss so people will pay attention to what the message is we wish to deliver."(The Hacktivist, 1999). Some arguments describe the hacktivism as illegal action and harming the victims by consider the use of viruses for hacking while on the contrary it has been suggested that viruses and worms are used by hacktivists to promote political messages. For instead in 1989 a political worm known as WANK targeted the HEPnet and the NASA SPAN networks to protest the development of nuclear weapons (Danning, p. 22). This action followed by 'Mawanella' a virus appeared in 2001 for describing the burning down of two mosques and one hundred Muslim-owned shops in Mawanella (Sophos, 2001).

\section{Hacktivism, Democracy Discourses and Global Changing}

"An international protest movement surfaced in resistance to neo-liberal institutions and their related globalization policies, while democracy, social justice, and a better world were championed. Since then, broad-based, populist political spectacles have become the norm, thanks to an evolving sense of the way in which the internet may be deployed in a democratic and emancipatory manner by a growing planetary citizenry that is using the new media to become informed, to inform others and to construct new social and political relations." (Richard Kahn and Douglas Kellner)

"Can the internet as a new public sphere serve as a home for democratic discourse?" 
The Internet's hospitality towards free speech is one of the reasons that democratic theorists often see it as a promising home for deliberative democracy. I prefer to quote a statement by Ranario (1998) "as global politics continue to endure a turbulent and complex time in history, an awareness of the hacktivism will continue expanding and envolving." Vegh within his desertation has concludes that:

"Articles on hackers and hacking increasingly use sensationalist tone and language, motivations are not discussed in news articles about hacking, the discourse is shifting from hackers as criminals to hackers as cyberterrorists, there is a larger focus on cyberterrorism now, even if it has not yet happened, the language of the media blurs the differences between hacktivism and cyberterrorism. True political dissent online is delegitimized by public opinion driven by the peculiar framing of media reports, which presents favorable conditions for passing laws and regulations that limit not only this mode of having alternative voices heard, but also other ways of conduct otherwise protected by the civil liberties and democratic principles." (Vegh 2003)

The hacktivism movement has been attracted different perceptions of public society. Some accepted it as a new phenomenon of political participation and communication in the modern era; hence the hacktivism movement could be one of the ways of democracy expansion while some rejected and uncompromised by the legal hacking computer methods build by the hacker-activists.

In other way, based on the Samuel's argument the hacktivism movement has raises questions about the way that free speech and anonymity have been formulated by theorists of deliberative democracy, and it also poses a larger problem for would-be discursive democrats. She mentioned that "hacktivism illustrates the challenge of enforcing any rules of deliberative discourse; without enforceable rules, the proceduralist vision of deliberative democracy may have to give way to a more amorphous form of online deliberation." According to Samuel "hacktivists can elude the mechanisms that allow states to enforce policy, pursuing policy circumvention rather than policy change. Also the keys are the characteristics that go along with hacktivism's digital nature: like most forms of Internet communication it can be anonymous, trans- and multinational, and take advantage of manyto-many and one-to many communications" (Samuel, 2007: 27). 
It may too early to make any prediction about the hacktivism movement and global changing but let me provide some arguments and research by scholars who concern on this issue. From Samuel (Ibid, 151), she stated "the promise of the transnational politics literature is clear from the moment we look at the possibility of applying its insights to the burgeoning phenomenon of hacktivism." Then she revealed a research finding from Keck and Sicking within the Activists Beyond Borders, which mentioned about the typical of transnational advocay Networks, "the centrality of values or principled ideas, the belief that individuals can make a difference, the creative use of information, and the employment by nongovernmental actors of sophisticated political strategies in targeting their campaigns." (Keck and Sikkink 1998). Therefore from that point of view "advocacy networks are helping to transform the practice of national sovereignty and an important part of an explanation for changes in world politics. These networks try not only to influence policy outcomes, but to transform the terms and nature of the debate." On the contrary, Danning (2001) argued that "hacktivists may feel a sense of empowerment, because they can control government computers and get media attention, but that does not mean they will succeed in changing policy. So far, anecdotal evidence suggests that for the majority of cases, they will not."

From those different arguments by the international scholars, yet we do need more researches on hacktivism and global changing in advance. But however, as we can see currently how the way of world moving on after the controversial of wikileaks, the way of hacktivism culture regarding on their responses to the global phenomenon and how those actions have been taken have changed the global politics and put more attentions into the freedom on internet and democracy discourses.

Based on my findings, through the internet, the freedom and democracy discourses have been promoted by prominent self-labeled hacktivist groups such as the Cult of the Dead Cow (cDc), the Electronic Disturbance Theater (EDT) and the Electro-Hippie Collective, etc. However hacktivism have been supplanting the technological ends of hackers with more humanistic goals, as Taylor argues "hacking, as it evolved over time, increasingly became the pursuit of technological means as an end in itself. Hacktivism, by contrast, is presented as a refocusing upon the political nature of the end to which technological means should be put: a normative element has been put back into objectified computer code." He then stated: 
"Whereas traditional politics are based on recruiting new members, developing unified strategies, democratic representation, and the pursuit of political hegemony, hacktivist politics involve the generation of broad umbrella spaces, where diverse organizations, collectives, and networks converge around a few common hallmarks, while maintaining their autonomy and specificity.” (Taylor, 2005).

Regarding on the way of hacktivists foster the democracy values through the internet need to be mentioned here that besides of several hacking politics actions, the EDT and Electrohippies, for example, have sections on their websites dedicated to explaining, justifying, and organizing calls for digital direct action (hacktions) prior to their start. These groups make their intentions public and even offer open forums for community discussions broadly. They are open groups that involve themselves into the global world with their real identities as same as the way of CDC has been contributed for the internet freedom and democracy.

Through this article, I argue that the hacktivism reflects the way of hacker activist to participate into the global politics by using their skills in hacking computer. Based on the Habermas' theory about the public sphere and political communication, the hacktivist use the media of internet as an effective public sphere for communicate their ideas and beliefs on politics. They do believe on freedom as the hackers culture themselves. They have been struggling for the free of information; free of speech; freedom on expression through the internet, those values are the main principles of something that we have been called democracy. They are a group of free people who rejected the authoritarian and more anarchy orientation, thus hackers are one of the important players for the maturity process of global politics.

\section{Conclusion}

"The government of the world must be entrusted to satisfied nations, who wished nothing more for themselves than what they had. If the world-government were in the hands of hungry nations, there would always be danger. But none of us had any reason to seek for anything more. The peace would be kept by peoples who lived in their own way and were not ambitious. Our power placed us above the rest. We were like rich men dwelling at peace within their habitations." (Winston Churchill) 
The quotation from Churchill above gives a message that between the government and the citizens should be appeared the balance role of state control. While government does their role, citizens monitor the processes and this method could be implemented by the political communication among. A political communication which involved public civil and the useful of technology could be described in several ways, and the internet works for the implementation of it.

Through the internet, the amounts of cyber activists who concern with the democracy discourses have been arising with the new social movement 'hacktivism'. The hacktivism is the combination of hacking techniques with political activism, struggling for the principle of freedom and promote the values of democracy through the internet. The hacktivits involve the technology hacking computer to convey their beliefs on politics and global world which the issues include human rights, global justice, freedom on internet, free flow of information, and free speech.

For this closing statement I like to reveal Taylor's conclusion regarding on the hacktivism movement "whatever the philosophical and practical differences may be between hacking and hacktivism, the key significance of hacktivism is the way in which it has produced a political strategy that is faithful to the combination of hacking's previously identified love of abstract systems as well as its commitment to the reappropriation and subversion of the original purposes of specific technological artefacts. (Taylor, Ibid: 9)

We are expecting for the implementation of the open society, the open government, and the open global communication in the modern era. Hence we want democracy to be implemented without making any deal with the authoritarian of any arbiters. While the hacktivism has promoted itself as a non-violent and accessible way for citizens to protest violations of our freedoms of information, as well as a wide variety of human rights injustices we can make some expectation about the global changing.

Finally I conclude that, as typically, hacktivism is a political participation in one hand, which civil people express their ideas about world politics and involve themselves into the political changing. In another hand, hacktivism is the way of political communication that benefited the internet media for share ideas, beliefs and conviction on politics, human rights among 
others within the global society. Thus in the study of media communication and technology, the way of internet can be use for the global changing exactly important nowadays. The global changing has emerging as fast as the technology development expanding itself to the whole of the world, making easier the way of people to communicate and participate into politics. This the way of communication, media, technology and politics will always synergy to explain the world phenomenon and shall be very interesting for the study of global changing, especially the way of democracy could be implemented.

Acknowledge: The author thanks to Umut Ayman PhD, Harry Ke T Ek, Devilzc0de, Indonesian and Wannabe Hacker Team, X-Code, Jasakom, and Binus Hacker.

Nofia Fitri was graduated from Political Science, National University of Indonesia, is a young researcher for politics and democracy issues, Indonesian Center for Islam and State Studies (www.psik-indonesia.org). Her research interests include politics, philosophy, media communication and technology (Computer and Internet).

Email: nofia.azriel@yahoo.co.id /nofia.fitri@binushacker.org, www.devilzc0de.org.

\section{References}

Bertrand Gauguet. For A Community Hacktivism Of Art. Parachute issue 102 - 2001

Busch, Otto von \& Palmås, Karl. (2006). Abstract Hacktivism: the making of a hacker culture. The United Kingdom: Lightning Source UK Ltd.

Cohen, S. (2002) Folk Devils \& Moral Panics: The Creation of the Mods and Rockers, 3rd Ed. London: Routledge.

Coleman, Gabriella \& Golub, Alex. (2008). Hacker practice: Moral genres and the cultural articulation of liberalism. Vol 8(3): 255-277, SAGE Publications.

Denning, D. (2000a) 'Activism, Hacktivism and Cyberterrorism,' Computer Security Journal, 16(3): 15-36.

Denning, D. (2000b) 'Cyberterrorism', Testimony before the Special Oversight Panel on Terrorism Committee on Armed Services, US House of Representatives, Washington DC. 
Denning, Dorothy E. (2001) 'Activism, Hacktivism, and Cyberterrorism: The Internet as a Tool for Influencing Foreign Policy', in John Arquilla and David Ronfeldt (eds), Networks and Netwars: The Future of Terror, Crime, and Militancy. Santa Monica: RAND Corporation, 239-88.

Friedland, Lewis A. "Electronic democracy and the new citizenship," Media, Culture \& Society 18, (1996): 185-212;

Gunkel, D. (2001) Hacking Cyberspace, Boulder CO: Westview Press.

Habermas, Jurgen. 1962. The Structural Transformation of the Public Sphere. Cambridge: Polity Press.

Halliday, Josh \& Arthur, Charles, WikiLeaks: Who are the hackers behind Operation Payback? Guardian.co.uk, Wednesday 8 December 2010.

Harasim, Linda M. Global Networks: Computers and International Communication (Cambridge, Mass.: MIT Press 1993)

Heidegger, M. (1977) The Question Concerning Technology and Other Essays. New York:Harper and Row.

Himanen, Pekka (2001) The Hacker Ethic, New York: Random House.

Hirzalla, Fadi. (2007). The Internet and Democracy: Participation Citizens and Politics. Vol. 14 (2007). No.2 pp. 83-96. Javnost, The Public.

John Street, "Remote Control? Politics, Technology and 'Electronic Democracy'," European Journal of Communication 12, no. 1 (1997): 27-42.

Jordan, T. and P. Taylor (2004) Hacktivism and Cyberwars: Rebels With a Cause? London: Routledge.

Juris, Jeffrey S. (2005) 'The New Digital Media and Activist Networking within AntiCorporate Globalization Movements', Annals of the American Academy of Political and Social Science, 597: 189-208.

Juris, Jeffrey S. (2007). Hacking Global Justice. Changing Politics through Digital Networks, October 5-6, 2007.

Kenneth L. Hacker, "Missing links in the evolution of electronic democratization," Media, Culture \& Society 18, (1996): 213-32.

Khan, Richard \& Kellner, Doughlas. (2004). New media and internet activism: from the 'Battle of Seattle' to blogging. London, Thousand Oaks, CA and New Delhi Klein, Naomi (2002) No Logo: No Space, No Choice, No Jobs. New York: Picador. 
Klein, Naomi, Computer Hacking New Tool of Political Activism, Toronto Star, July 23, 1998.

Levy, Stephen (1984) Hackers: Heroes of the Computer Revolution, New York: Bantam Doubleday Dell.

Mansell, Robin. Communication and Technology: What's New? LSE-EDS Seminar, 21 November 2007.

McPhillips, Fiona. Internet Activism: Towards Framework for Emergent Democracy. IADIS International Conference WWW/Internet 2006.

Meikle, Graham (2002) Future Active: Media Activism and the Internet. New York and London: Routledge.

Miller, Paul. Open Policy: Threats and opportunities in a wired world. Forum for the Future, 19-23 Ironmonger Row, London EC1V 3QN.

Samuel, Alexandra Whitney. (2004). Hacktivism and the Future of Political Participation. Cambridge, Massachusetts: Harvard University.

Surman, Mark \& Reilly, Katherine. 2003. Appropriating the Internet for Social Change: Towards the strategic use of networked technologies by transnational civil society organizations. Social Sciences Research Council. Information Technology and International Cooperation Program.

Taylor, Paul (1999) Hackers: Crime in the Digital Sublime. Routledge: London.

Taylor, Paul A. (2005). From hackers to hacktivists: speed bumps on the global superhighway? London, Thousand Oaks, CA and New Delhi. Vol7(5):625-646. SAGE Publications.

\section{Websites:}

http://www.cultdeadcow.com

http://www.hacktivism.org

http://www.wired.com

http://thehacktivist.com 